\title{
Hospital Accreditation: A Review of Evidence, Regulatory Compliance, and Healthcare Outcome Measures
}

\author{
Khamis Al-Alawy ${ }^{a}$ Immanuel Azaad Moonesar ${ }^{b}$ Hanan Ali Mubarak Obaid ${ }^{a}$ \\ Ehab Ismail Al-Abed Bawadi ${ }^{a}$ Reem Gaafar ${ }^{b}$ \\ ${ }^{a}$ Health Regulation Sector, Dubai Health Authority, Dubai, UAE; ${ }^{b}$ Health Administration and Policy, Mohammed Bin \\ Rashid School of Government, Dubai, UAE
}

\section{Keywords}

Hospital · Accreditation · Regulation · Health policy ·

Healthcare quality

\section{Abstract}

Background: Hospitals are increasingly under pressure to provide safe and high-quality care at an affordable cost. In response to this challenge, many have adopted accreditation as an internationally recognized tool to facilitate improvements in healthcare quality and patient safety. The objectives of the study were to (a) evaluate the impact of international hospital accreditation in Dubai and (b) inform policy decision-making. Methods: We adopted a literature review, analysis of violation data, and clinical performance measures. Results: The literature review suggests insufficient evidence to link accreditation to healthcare outcomes. We report a gradual increase in hospital violations and an improvement of clinical outcomes over three years, however the improvement in clinical outcome measures were not statistically significant. Conclusions: There is limited evidence to determine the impact of international hospital accreditation. Performance measures for accreditation are needed to validate the contribution accreditation may have on reducing non-compliance and improving clinical performance measures. Further research is needed to explore how well accreditation models fit within the Donabedian framework for healthcare quality.

(C) 2021 The Author(s)

Published by S. Karger AG, Basel

\section{Introduction}

Hospitals are increasingly under pressure to provide efficient, safe, and high-quality care at an affordable cost. In response to this challenge, many have adopted accreditation as an internationally recognized tool to facilitate improvements in healthcare quality. Accreditation was initiated in the 1960s and has manifested into an industry recognized by providers, insurers, and regulators alike. Over the past two decades, there has been a fruition of hospital accreditation organizations at the local and international level [1]. Accreditation is understood as an assessment process against set standards and may be voluntary (self-regulatory), or in some instances a mandatory requirement for example, where it has been man- karger@karger.com www.karger.com/dmj

Karger $\stackrel{\text { ' }}{5}$

BOPEN ACCESS
(C) 2021 The Author(s)

Published by S. Karger AG, Basel

This is an Open Access article licensed under the Creative Commons Attribution-NonCommercial-4.0 International License (CC BY-NC) (http://www.karger.com/Services/OpenAccessLicense), applicable to the online version of the article only. Usage and distribution for commercial purposes requires written permission.
Correspondence to:

Khamis Al-Alawy, kalalawy@dha.gov.ae 
dated for licensure, reimbursement or quality improvement [2]. However, there are differing viewpoints on its effectiveness in improving healthcare outcomes $[1,3-6]$. Furthermore, the cost of accreditation is perceived as a barrier for smaller healthcare organizations seeking accreditation $[7,8]$. Our institution is the custodian and regulator of the health sector and plays a key role in supporting foreign and local investment, growth, and sustainability. In 2014, our institution issued a policy to mandate international hospital accreditation [9]. Accreditation was seen as an opportunity to improve healthcare practice and support the growth of medical tourism. Accreditation bodies under the International Society for Quality in Health Care that were approved during the study period and include the Australian Council on Healthcare Standards, Joint Commission International, and Accreditation Canada International [9]. The process for accreditation usually starts once a work group is formed and may include clinical and non-clinical staff across hospital departments. The scope and function of the work group may be varied and dependant on current standing and typically includes risk assessment and gap analysis, preparatory work for an on-site survey and development of internal policies and procedures and improvement plans to evidence achievement against accreditation standards. Accredition staff may be independent contractors working across different countries to provide independent and expert assessment and advice to achieve the accredition standards. Cost for accreditation may be dependent on several factors including but not limited to the health facility's accreditation status, duration, size of the institution, and the number of required visits. The objectives of the study were to (a) evaluate the impact of international hospital accreditation and (b) inform policy decision-making.

\section{Methods}

Our study set out to evaluate the impact of hospital accreditation through a review of literature, violation data and healthcare outcomes using the Donabedian framework for healthcare quality (structure, process and outcome) $[10,11]$. Given the limitation on timeframe and resources, we adopted a retrospective summative study design. Our approach supports complex policy decisionmaking and is useful where longitudinal data sets and study controls are not in place prior to policy implementation [8, 12-15]. Furthermore, the collection of data at a single point aids efficient utilization of limited resources within a defined timeframe following the implementaiton of policy.

The literature review included desk searches on the impact of the hospital accreditation from Ovid/MEDLINE, Scopus, and
Google Scholar, (2002-2019, English only). Peer-reviewed studies investigating the impact of accreditation were identified, analyzed, and summarized using a summary table that adopted the key parameters of the Donabedian framework. Literature reviews are useful because they are cost-effective, useful in supporting research and evaluation, and provide insight into current gaps, available tools, frameworks, methods, analysis, and discussion. Additionally, literature reviews capture best practice and provide current understanding and different perspectives on the subject of interest [12].

Policy announcement for international hospital accreditation took place in 2014 but was not enforceable until 2016 [9]. This is because there is a time delay between policy announcement and achievement of accreditation which includes survey assessment, compliance against set standards, compliance with local regulations, and system-wide improvement within the hospital setting. We sought to explore the effect of hospital accreditation from (a) when accreditation was enforceable (2016), and (b) when violation data were fully available (2017). These two points were used as the baseline to evaluate the impact of hospital accreditation. Accreditation status and aggregated violation data were captured by our organization clinical audit and control department for private hospitals up until 2019. In total, twenty-five private hospitals were accredited and reviewed for non-compliance of local regulations. Public sector hospitals were not under the legal jurisdiction of our organization therefore, violation data was not available between 2017 and 2019. Violations were in relation to the structure and process components of the Donabedian framework and were categorized by the clinical audit team as minor (administrative) and major (technical) as per exisiting regulations [10]. The violation data were utilized to determine if any change was observed in the number of violations issued between 2017 and 2019 .

In 2016, a mandate was introduced by the Executive Council for all hospitals to self-report their performance against several outcome performance measures to our organization. The hospital outcome measures align with the outcome component of the Donabedian framework and included device-related hospital-acquired infections (HAIs) (ventilator-associated pneumonia [VAP], catheter-associated urinary tract infection, and central line bloodstream infection [CLABSI]), medical error (ME), surgical site infections (SSIs), length of stay (LOS), and unplanned readmissions (URs). Between 2016 and 2019, we analyzed the performance of the twenty-five private hospitals even though four more private hospitals were licensed during the study period. This was because (a) the twenty five hospitals were accredited, (b) matched with the same twenty-five hospitals that were reviewed for number of violations, and (c) outcome data between 2016 and 2019 were readily available. Accreditation and outcome data for the four public hospitals between 2016 and 2019 were also included. Performance against target for twenty-five private and four public hospital data were provided by the clinical audit and control department, analysed and summarised using spreadsheet then presented in two tables. The before and after analysis for hospital outcome measures was performed using SPSS Subscription Version (2021). We calculated the mean and standard deviations, and standard error of the mean between 2016 and 2019. The paired $t$ test was used to compare the mean KPI values between 2016 and 2019 with a $95 \%$ confidence interval which is presented in a table. 


\section{Results}

\section{Literature Review}

A summary of the literature review is available online (suppl. material 1; for all online suppl. material, see www.karger.com/doi/10.1159/000516483). Eighteen English studies between 2002 and 2019 were identified [16-33]. Main outcome measures were varied and included accreditation status, organizational characteristics, clinical outcomes, staff perceptions and experiences, the achievement of standards, hospital readiness for integration, implementation, and cost-effectiveness. Only one study reported on all three domains (structure, process, and outcome). Studies included were from a variety of countries (Zambia, Jordan, Lebanon, Iran, Turkey, the Kingdom of Saudi Arabia, Portugal, and the USA).

\section{Structure}

Accreditation was reported to have had a positive impact on structure, four of the six studies included reported improvement through structure measures [21, $26,31,33]$. Improvements were observed in the quality improvement principle (11.1\%), patient/service user focus principle $(22.2 \%)$, with the majority of improvement in the safety principle (70\%), $12.8 \%$ reduction in staff turnover, and $20.0 \%$ improvement in the completeness of medical records and organizational structure.

\section{Process}

Three studies reported on process measures. The first study indicated the need to improve processes to match the International Society for Quality in Health Care standards [21]. The second reported on staff surveys and highlighted an improvement in medication and labeling processes as well as infection control standards [27]. The third study reported an improvement in the communication processes for reporting of medical error (ME) and non-MEs and documentation [31]. None of the studies included reported improvement in processes through validated process measures.

\section{Outcome}

Findings on outcome varied, some studies reported improvement in specialized or smaller institutions with a noticeable improvement in the acute myocardial infarction, trauma, and chest pain management within $24 \mathrm{~h}$, survival rates for blunt trauma, the shelf life in Intensive Care Unit, LOS, and mortality [17, 21, 22, 26, 29, 32]. Three of the six studies reported statistical significance in their findings [26, 31, 32]. Halasa et al. [26] explored the cost impact of an international accreditor. The total saving from combining two measures (reduction in return to the intensive care unit within $24 \mathrm{~h}$ of discharge and reduction in staff turnover) was USD 296,655 per hospital over 3 -years. Aggregate saving were reported to be USD 593,310 for the health system for two accredited hospitals). Almasabi and Thomas [31] reported a decline in hospital mortality, HAI and LOS from staff self-reporting and interviews. Review of documentation suggests the impact on mortality rates were neutral with significance in HAI between three hospitals $(p=0.0026,0.0001$, and 0.0007 , respectively), but there was no observed overall improvement ( 1 decreased and 2 increased). Lam et al. [32] reported on several indicators but only found statistical significance for readmissions for 15 medical conditions at 30 days between accredited hospitals when compared to state survey hospitals (22.4\% vs.23.2\%, $0.8 \%$ [0.4\% to $1.3 \%], p<0.001)$.

\section{Hospital Violations (Private Sector)}

Hospital violations were categorized into minor (administrative) and major (technical) violations as per the Decree of the Dubai Executive Council No. 32 of 2012 (Penalties for Ethical and Technical Violations [Committee Discussion] and Fines for Administrative Violations [Facilities and Professionals Fines]) [10]Minor violations for the twenty-five private hospitals from 2017 to 2019 were 6,4 , and 4 , and major violations were 5,10 , and 14 . We report an increase in the total number of reported violations between 2017 and 2019 (11, 14, and 18, respectively).

\section{Hospital Performance (Private and Public Sectors)}

The findings for hospital performance measures across the private and public hospitals are presented in Tables 1 and 2. The desired outcome for device-related HAI included VAP, catheter-associated urinary tract infection, and CLABSI is to minimize the rate of acquired infections in the hospital and minimize the risk and associated morbidity and mortality [34-38]. The results suggest good performance against the target with a decreasing trend in overall infection rates against the target. The desired outcome for ME is to identify the preventable $\mathrm{ME}$ and to minimize the risks, unnecessary harm, and mortality resulting from ME [39]. The results suggest good performance against the target but with an increasing trend between 2018 and 2019 in the private and public sector. This was the only indicator with a similar baseline between the private and public sectors. The 
Table 1. Private hospital healthcare outcome trends (2016-2019)

\begin{tabular}{|c|c|c|c|c|c|c|}
\hline & Target & $\begin{array}{l}\text { performance } \\
2016\end{array}$ & $\begin{array}{l}\text { performance } \\
2017\end{array}$ & $\begin{array}{l}\text { performance } \\
2018\end{array}$ & $\begin{array}{l}\text { performance } \\
2019\end{array}$ & Trend \\
\hline DHAI $^{* *}$ & 2.5 & 1.54 & 3.3 & 1.67 & 0.6 & \\
\hline $\mathrm{ME}$ & 38 & 15.47 & 8.6 & 10.12 & 10.82 & $\begin{array}{llll}0 & 0 & 0 & 0\end{array}$ \\
\hline LOS & 2.12 & 2.38 & 2.23 & 2.16 & 1.62 & $\begin{array}{llll}0 & 0 & 0 & 0\end{array}$ \\
\hline UR & 0.38 & 0.75 & 0.58 & 0.49 & 0.45 & $\begin{array}{llll}0 & 0 & 0 & 0\end{array}$ \\
\hline
\end{tabular}

DHAI, device-related hospital-acquired infection; VAP, ventilator-associated pneumonia; CAUTI, catheter-associated urinary tract infection; CLABSI, central line bloodstream infection; ME, medical error; SSI, surgical site infection; LOS, length of stay; UR, unplanned readmission. ${ }^{*} 25$ private hospitals with complete data sets (2016-2019). ${ }^{* *}$ Device-related hospital-acquired infections (ventilator-associated pneumonia [VAP], catheter-associated urinary tract infection [CAUTI] and central line bloodstream infection [CLABSI]).

Table 2. Public hospital healthcare outcome trends (2016-2019)

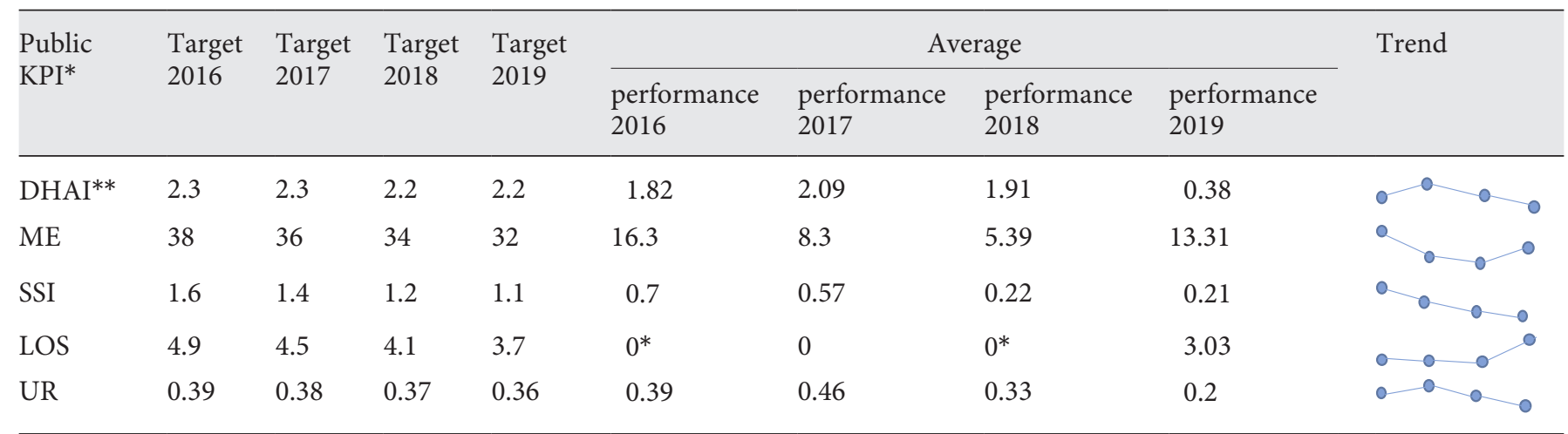

DHAI, device-related hospital-acquired infection; VAP, ventilator-associated pneumonia; CAUTI, catheter-associated urinary tract infection; CLABSI, central line bloodstream infection; ME, medical error; SSI, surgical site infection; LOS, length of stay; UR, unplanned readmission.* 4 public hospitals with complete data sets (2016-2019). ${ }^{* *}$ Device-related hospital-acquired infections (ventilator-associated pneumonia [VAP], catheter-associated urinary tract infection [CAUTI] and central line bloodstream infection [CLABSI]).

findings for SSI suggest good performance against the target with the greatest improvements reported between 2018 and 2019. Polarity is negative even with known increases in the number of surgeries during the study period [40]. The desired outcome for LOS is to identify the efficiency of healthcare services and maximize the efficient management of hospital bed days, which may be achieved through ambulatory care, prehospital intervention and post-acute care [41]. The findings suggest good performance against the target. The data for the public sector was not fully available between 2016 and 2018 . Public sector performance suggests an increase in LOS between 2018 and 2019 but remained below the target. For UR within 28 days, the desired outcome is to measure efficiency, effectiveness, and prevent readmissions and avoidable bed days [42]. The data suggest a decreasing trend for both private and public sector. The private sector had missed the target over the study period by a small margin.

The before and after statistical analysis for twentyfive private sector hospitals between 2016 (baseline) and 2019 is presented in Table 3 . The four public hospital data were not conclusive due to a change in measurements and targets between 2017 and 2019 and 
Table 3. Private hospital trends (2016 and 2019)*

\begin{tabular}{|c|c|c|c|c|c|c|c|c|c|}
\hline \multirow{2}{*}{$\begin{array}{l}\text { Key } \\
\text { performance } \\
\text { indicator }\end{array}$} & \multicolumn{2}{|c|}{ Mean } & \multicolumn{5}{|c|}{ Paired differences } & \multirow[t]{2}{*}{$p$ value $e^{* * *}$} & \multirow{2}{*}{$\begin{array}{l}\text { Level of } \\
\text { significance }\end{array}$} \\
\hline & $\begin{array}{l}2016 \\
\text { (before) }\end{array}$ & $\begin{array}{l}2019 \\
\text { (after) }\end{array}$ & $\begin{array}{l}\text { mean } \\
\text { difference }\end{array}$ & $\begin{array}{l}\text { std. } \\
\text { deviation }\end{array}$ & $\begin{array}{l}\text { std. error } \\
\text { mean }\end{array}$ & \multicolumn{2}{|c|}{$95 \% \mathrm{CI}$ of the difference } & & \\
\hline UR & 0.504 & 0.402 & 0.102 & 0.710 & 0.142 & -0.191 & 0.395 & 0.478 & $\begin{array}{l}\text { Not statistically } \\
\text { significant }\end{array}$ \\
\hline $\mathrm{ME}$ & 13.588 & 8.501 & 5.087 & 12.713 & 2.543 & -0.161 & 10.335 & 0.057 & $\begin{array}{l}\text { Not statistically } \\
\text { significant }\end{array}$ \\
\hline $\mathrm{UTI}^{* *}$ & 0.556 & 0.440 & 0.116 & 1.343 & 0.269 & -0.438 & 0.670 & 0.670 & $\begin{array}{l}\text { Not statistically } \\
\text { significant }\end{array}$ \\
\hline $\mathrm{SSI}^{* *}$ & 0.220 & 0.220 & 0.000 & 0.189 & 0.038 & -0.078 & 0.078 & 1.000 & $\begin{array}{l}\text { Not statistically } \\
\text { significant }\end{array}$ \\
\hline
\end{tabular}

VAP, ventilator-associated pneumonia; CLABSI, central line bloodstream infection; ME, medical error; SSI, surgical site infection; LOS, length of stay; UR, unplanned readmission; UTI, urinary tract infection; CI, confidence interval; DHAI, device-related hospitalacquired infections. ${ }^{*}$ Twenty-five private hospitals (the four public hospital data were not conclusive since the measurements and targets were changed between 2017 and 2019. ** DHAIs (VAP, CAUTI and CLABSI, SSI). *** $t$ test: Paired 2 Sample for Means using SPSS, Statistics.

therefore not included. The findings for private hospitals suggest the differences in the means were too small, and the ranges for each hospital outcome indicator were varied. The correlation between the variables indicate that the measures taken to mitigate against infection rates (VAP, UTI, CLABSI, and SSI), and other variables (UR, LOS, and ME) between 2016 and 2019 were not statistically significant for all outcome measures.

\section{Limitations}

The literature review may have excluded studies due to the choice of databases used. Furthermore, it might have been appropriate to extend the search filters to capture the additional articles on the impact of hospital accreditation. The violation data were only available for the private sector due to our institution regulatory scope and governance arrangements. Only twenty-five (out of 30) private hospital data were utilized to ensure the same hospitals were being measured for regulatory non-compliance and healthcare outcomes following the achievement of accreditation in 2016. It remains challenging to associate the increase in the total number of violations issued due to accreditation albeit accreditation is a system-wide intervention for improvement. An increase in violations may be proportionate to other factors such as additional regulatory measures or an increase in the number additinal services provided by the hospital provider between 2017 and 2019. The baseline and targets for public and private sector hospital beween 2016 and 2019 were not the same for all measures which made it difficult to compare the performance between the two sectors. Comparative and statistical analysis of hospital outcome data against the control was not feasible due to the nature of policy-wide implementation of hospital accreditation across all the private hospitals. Furthermore, statistical analysis for hospital outcome measures was only possible for twenty-five (out of 30) private hospitals between 2016 and 2019 that had complete data sets. The study excluded other possible indicators that could be considered as part of the Donabedian framework, such as staffing ratio, compliance with care pathways, patient satisfaction, and waiting time. This was primarily due to the availability of data sets between 2016 and 2019. 


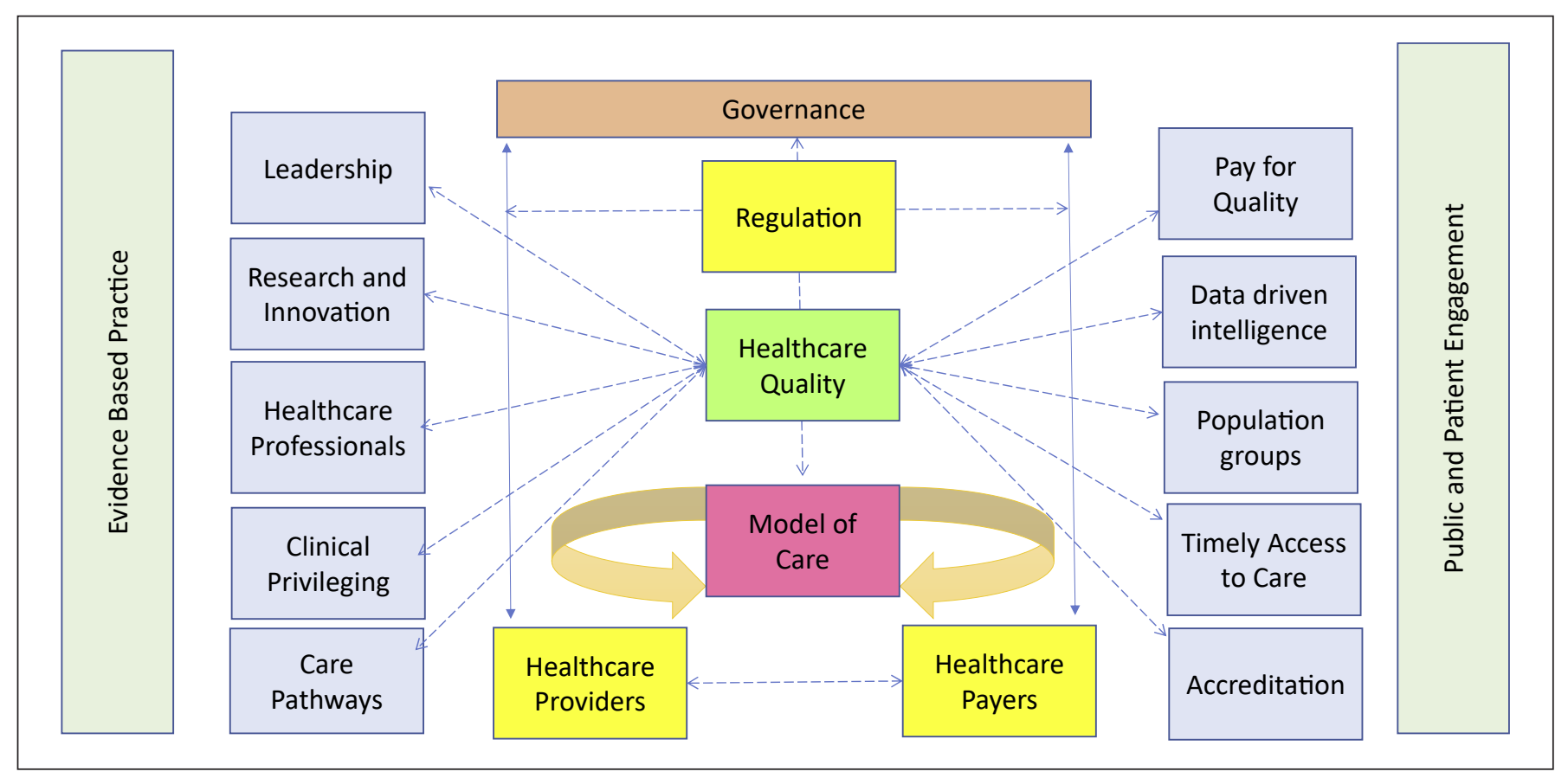

Fig. 1. Factors that influence healthcare quality.

\section{Discussion}

The findings from the literature review demonstrate the proliferation of accreditation across the globe. This creates heterogeneity of study designs and methods offering insight and different perspectives but equally makes it difficult to standardize approaches for evaluation and conducting comparative assessment on structure, process, and outcome [43]. While accreditation may be perceived to have had a positive impact on the hospital performance, validated indicators to measure the structure, process, and outcome were limited. Bartlett suggest there is a lack of influence between structure and outcome and between the process and outcome [44]. Merkow et al. [45] conclude that accredited facilities perform well on the process measures but not on the outcome. Griffith et al. [46] and Vallejo et al. [47] suggest that structural and process standards are more accessible and tangible than outcome measures. We further this perspective and suggest that outcomes are dependent on good governance, regulation, payer, and provider interactions, and the model of care, among many other factors (Fig. 1). The combination of these factors present challenges in a linearity approach or with generic hospital interventions to influence outcome. The focus on too many and at times, conflicting processes, and documentation places risk for lots of activity with either limited improvement or improvement in areas deemed unimportant. Thus, there is a need to rethink what processes have the most impact on the outcomes as well as the opportunity for healthcare providers to leapfrog from structure to outcome [48].

While data on hospital violations may not be directly associated with accreditation, there are two perspectives worth considering. First, the increase in violations may be due to an increase in regulatory requirements or the number of hospital services over the study period. Second, there are gaps in accreditation demonstrated through an increase in violations. It is likely that time spent on accreditation offsets the amount of time spent on meeting regulatory compliance, which in turn has financial and licensing implications for the provider. Thus, the trade-off between accreditation and regulatory requirements is likely to place hospital providers in an unfavorable position whereby senior management are at a peril between ensuring the requirements for accreditation are met with the risk of regulatory action due to regulatory non-compliance. The hospital data suggest an improvement across the clinical indicators for both private and public sectors against the target; however, demonstrating causation between accreditation and performance remains challeng- 
ing. The statistical analysis in 2016 and 2019 indicates an improvement between the two means but were not statistically significant. This suggests that all interventions, including accreditation, were insufficient to demonstrate a statistical improvement in the outcome measures and may highlight gaps in structure and processes. The observed variation of targets between the private and public sectors suggests the need to assure uniformity of definitions and targets to provide a more accurate view of hospital performance across the health sector.

\section{Conclusions}

There is limited evidence to determine the impact of hospital accreditation. Performance measures for accreditation are needed to validate the contribution accreditation may have on reducing non-compliance and improving clinical performance measures. Further research is needed to explore how well accreditation models fit within the Donabedian framework for healthcare quality.

\section{Implications}

There are several implications from the study. First, the scope of accreditation should align with the regulatory and healthcare system performance measures. Second, performance measures are needed to determine what role accreditation plays toward reducing violations and improving clinical performance. Third, performance measures may provide insight on the accreditor and delivery model that is superior or most suited for the local health- care system. Finally, other data sources are needed to determine the impact of hospital accreditation, such as patient and staff satisfaction and complaince with e-claims.

\section{Statements of Ethics}

Ethical approval was not required as the study formed part of an evaluation to inform policy decision-making and did not include confidential or patient identifiable information.

\section{Conflict of Interest Statement}

The authors have no conflicts of interest to disclose.

\section{Funding Sources}

The author(s) disclosed receipt of the following financial support for the research, authorship, and/or publication of the manuscript. The authors would like to acknowledge Mohammed Bin Rashid School of Government, Dubai, UAE, and the Alliance for Health Policy and Systems Research at the World Health Organization for the financial support as part of the Knowledge to Policy (K2P) Center Mentorship Program (BIRD Project).

\section{Author Contributions}

K.A.: project lead, conceptual design, drafting of the manuscript, interpretation of the data, final approval, and accountability. I.A.M.: conceptual design, editing, data analysis and interpretation, final approval, and accountability. H.A.M.O.: conception of work, critical review and revision, final approval, and accountability. E.I.A.B.: conceptual design, data analysis, drafting/editing, final approval, and accountability. R.G.: conceptual design, drafting of the manuscript, final approval, and accountability.

\section{References}

1 Duckett SJ. Changing hospitals: the role of hospital accreditation. Soc Sci Med. 1983; 17(20):1573-9.

2 Center for Medicare and Medicaid Services. Accreditation of medicare certified providers \& suppliers. 2020. Available from: https://www. $\mathrm{cms}$.gov/Medicare/Provider-Enrollment-andCertification/SurveyCertificationGenInfo/Accreditation-of-Medicare-Certified-Providersand-Suppliers. Accessed 2020 Dec 12.

3 Healy J. Improving health care safety and quality: reluctant regulators (Law, ethics and governance). London: Routledge; 2011. p. $1-328$.

4 AlKhenizan A, Shaw C. Impact of accreditation on the quality of healthcare services: a systematic review of the literature. Ann Saudi Med. 2011 Jul-Aug;31(4):407.
5 Pomey M-P, Contandriopoulos A-P, François P, Bertrand D. Accreditation: a tool for organization change in hospitals? Int J Health Care Qual Assur. 2004;17:113-24.

6 Robblee J, Heidemann E. Hospital accreditation and the surgeon: the Canadian experience. Surgeon. 2004;2(6):321-6.

7 Zarkin GA, Dunlap LJ, Homsi G. The costs of pursuing accreditation for methadone treatment sites: results from a national study. Eval Rev. 2006 Apr;30(2):119-38.

8 Greenfield D, Braithwaite J. Health sector accreditation research. A systematic review. Int J Qual Health Care. 2008;20:172-83.

9 Dubai Health Authority. Hospital accreditation policy. Health Regulation Department, Health Regulation Section; 2014.
10 Decree of the Executive Council No. (32) Of 2012 concerning the regulation of practicing health professions in the Emirate of Dubai. https://www.dha.gov.ae/en/HealthRegulation/ Pages/about.aspx. Accessed 12 Jan 2020.

11 Donabedian A. Evaluating the quality of medical care. Milbank Q. 2005;83(4):691-729.

12 Cowell JM. The advantage of literature reviews for evidence-based practice. J Sch Nurs. 2015;31(1):5

13 Wang M, Beal DJ, Chan D, Newman DA, Vancouver JB, Vandenberg RJ. Longitudinal research: a panel discussion on conceptual issues, research design, and statistical techniques. Workar. 2017;3(1):1-24.

14 Caruana EJ, Roman M, Hernández-Sánchez J, Solli P. Longitudinal studies. J Thorac Dis. 2017;7:E537-40. 
15 Kehr F, Kowatsch T. Quantitative longitudinal research: a review of IS literature, and a set of methodological guidelines. 2015.

16 Bukonda N, Tavrow P, Abdallah H, Hoffner $\mathrm{K}$, Tembo J. Implementing a national hospital accreditation program: the Zambian experience. Int J Qual Health Care. 2002;14(Suppl 1):7-16.

17 El-Jardali F, Jamal D, Dimassi H, Ammar W, Tchaghchaghian V. The impact of hospital accreditation on quality of care: perception of Lebanese nurses. Int J Qual Health Care. 2008; 20(5):363-71.

18 Pomey M-P, Lemieux-Charles L, Champagne F, Angus D, Shabah A, Contandriopoulos A-P. Does accreditation stimulate change? A study of the impact of the accreditation process on Canadian healthcare organizations. Implement Sci. 2010;5:31.

19 Greenfield D, Pawsey M, Braithwaite J. What motivates professionals to engage in the accreditation of healthcare organizations? Int J Qual Health Care. 2011;23(1):8-14.

20 AlKhenizan A, Shaw C. Assessment of the accreditation standards of the Central Board for accreditation of healthcare institutions in Saudi Arabia against the principles of the International Society for Quality in Health Care (ISQua). Ann Saudi Med. 2010;30(5):386

21 AlKhenizan A, Shaw C. Impact of accreditation on the quality of healthcare services: a systematic review of the literature. Ann Saudi Med. 2011;31(4):407-16.

22 El-Jardali F, Jaafar M, Jamal D, Rabbaa S. Integrating patient safety standards into the accreditation program: a qualitative study to assess the readiness of Lebanese hospitals to implement into routine practice. J Patient Saf. 2012;8(3):97-103.

23 Saleh SS, Sleiman JB, Dagher D, Sbeit H, Natafgi N. Accreditation of hospitals in Lebanon: is it a worthy investment. Int J Qual Health Care. 2013;25(3):284-90.

24 Yildiz A, Sidika K. Perceptions of nurses on the impact of accreditation on quality of care: a survey in a hospital in Turkey. Clin Gov Intern J. 2014;19(2):69-82.

25 Brubakk K, Vist GE, Bukholm G, Barach P, Tjomsland O. A systematic review of hospital accreditation: the challenges of measuring complex intervention effects. BMC Health Serv Res. 2015; 15:280.
26 Halasa YA, Zeng W, Chappy E, Separd DS. Value and impact of international hospital accreditation: a case study from Jordan. East Mediterr Health J. 2015;21(2):90-9.

27 Shammari MA, Habib SA, Shubrami DA, Rashidi MA. Impact of hospital accreditation on patient safety in Hail city Saudi Arabia: nurse perspective. IOSR J Nurs Health Sci. 2015;4(1):51-5.

28 Galukande M, Katamba A, Nakasujja N, Baingana R, Bateganya M, Hagopian A, et al. Developing hospital accreditation standards in Uganda. Int J Health Plann Manage. 2016; 31:e204-18.

29 Janati A, Tabrizi JS, Toofan F, Algalandis KN, Ebrahimoghli R. Hospital accreditation: what is its effect on quality and safety indicators? Experience of an Iranian Teaching Hospital. Bali Med J. 2016;5(2):303-7.

30 Melo S. The impact of accreditation on healthcare quality improvement: a qualitative case study. J Health Organ Manag. 2016; 30(8):1242.

31 Almasabi M, Thomas S. The impact of Saudi hospital accreditation on quality of care: a mixed methods study. Int $J$ Health Plann Manage. 2017;32:e261-78.

32 Lam MB, Figueroa JF, Feyman Y, Reimold KE, Orav EJ, Jha AK. Association between patient outcomes and accreditation in US hospitals: observational study. BMJ. 2018;363: k4011.

33 Bogh SB, Blom A, Raben DC, Braithwaite J, Thude B, Hollnagel E, et al. Hospital accreditation: staff experiences and perceptions. Int J Health Care Qual Assur. 2018;31(5): 420-7.

34 Weinstein RA, Darouiche RO. Device-associated infections: a macroproblem that starts with microadherence. Clin Infec Dis. 2001 Nov 1;33(9):1567-72.

35 Maki DG, Stolz SM, Wheeler S, Mermel LA Prevention of central venous catheter-related bloodstream infection by use of an antisepticimpregnated catheter: a randomized, controlled trial, Ann Intern Med. 1997;127:25766.

36 Di Filippo A, De Gaudio AR. Device-related infections in critically ill patients. Part II: prevention of ventilator-associated pneumonia and urinary tract infection. J Chemother. 2003 Dec;15(6):536-42.
37 Cortese YJ, Wagner VE, Tierney M, Devine D, Fogarty A. Review of catheter-associated urinary tract infections and in vitro urinary tract models. J Healthc Eng. 2018;2018: 2986742.

38 Spencer M. Central-line infections. Am J Nurs. 2014;114(12):13.

39 Greengold NL. The impact of dedicated medication nurses on the medication administration error rate: a randomized controlled trial. Arch Intern Med. 2003 Oct 27;163(19):235967.

40 Fukuda H, Morikane K, Kuroki M, Taniguchi S, Shinzato T, Sakamoto F, et al. Toward the rational use of standardized infection ratios to benchmark surgical site infections. Am J Infect Control. 2013 Sep;41(9):810-4.

41 Vinh KP, Walston SL, Szychowski J, Hernandez SR. The effect of hospitalists on average length of stay. J Healthc Manag. 2019 MayJun;64(3):169-84.

42 Fischer C, Lingsma HF, Marang-van de Mheen PJ, Kringos DS, Klazinga NS, Steyerberg EW. Is the re-admission rate a valid quality indicator? A review of the evidence. PLoS One. 2014;9(11):e112282.

43 Jaafaripooyan E, Agrizzi D, Akbari-Haghighi F. Healthcare accreditation systems: further perspectives on performance measures. Int $J$ Qual Health Care. 2011;23(6):645-56.

44 Bartlett $\mathrm{H}$. Nursing homes for elderly people: questions of quality and policy. London: Routledge; 1993.

45 Merkow RP, Chung JW, Paruch JL, Bentrem DJ, Bilimoria KY. Relationship between cancer center accreditation and performance on publicly reported quality measures. Ann Surg. 2014;259:1091-7.

46 Griffith JR, Knutzen SR, Alexander JA. Structural versus outcomes measures in hospitals: a comparison of Joint Commission and Medicare outcomes scores in hospitals. Qual Manag Health Care. 2002;10(2):29.

47 Vallejo BC, Flies LA, Fine DJ. Comparison of hospital accreditation programs. J Clin Eng. 2011;36(1):32-8.

48 Ashish K. Accreditation, quality, and making hospital care better. JAMA. 2018 Dec 18; 320(23):2410-1.
Evidence, Regulatory Compliance, and Healthcare Outcome Measures
Dubai Med J 2021:4:248-255 